\title{
Serological evidence of canine influenza virus infection in shelter dogs in Turkey
}

\author{
HAKAN AYDIN, AKIN KIRBAS*, MEHMET OZKAN TIMURKAN, \\ MUSTAFA SINAN AKTAS*, GULIZAR ACAR KIRMIZI, OMER AYDIN*
}

\begin{abstract}
Department of Virology, Faculty of Veterinary Medicine, Ataturk University, Erzurum, Turkey
*Department of Internal Medicine, Faculty of Veterinary Medicine, Ataturk University, Erzurum, Turkey
\end{abstract}

Aydin H., Kirbas A., Timurkan M. O., Aktas M. S., Kirmizi G. A., Aydin O. Serological evidence of canine influenza virus infection in shelter dogs in Turkey

Summary

Influenza virus infection is an important disease which occurs in humans and a variety of animals. Because of the wide host adaptation and segmented genome, there is always the possibility of mutations and interspecies transmission of the influenza virus. Our study is the first to draw attention to canine influenza infection in Turkey. For this purpose, 208 sera and swab samples were collected from dogs with respiratory and nonrespiratory signs in various seasons. Out of the $208 \mathrm{dogs}, 94(45.2 \%)$ were male and $114(54.8 \%)$ were female; the average age was 4.7 years. A total of 208 sera samples were tested for the presence of canine influenza virusspecific antibodies by the indirect enzyme-linked immunosorbent assay. The seroprevalence of canine influenza virus infection was $11 / 208(5.8 \%)$. With regard to seasonal distribution, the highest rate of seropositivity was detected in spring, and the lowest in summer. Molecular detection of the canine influenza virus from nasal swab samples was done by reverse transcriptase polymerase chain reaction using specific universal primers for the hemagglutinin gene. Influenza virus nucleic acid could not be detected by reverse transcriptase polymerase chain reaction. In this study, we revealed for the first time the existence of the canine influenza virus in Turkey. Although the seroprevalence was relatively low, it would be useful to investigate the canine influenza virus on a large scale and among dogs with infectious respiratory disease in the Turkish dog population.

Keywords: dog flu, seroprevalence, ELISA, PCR

The influenza A virus belongs to the genus Orthomyxovirus, which is classified into subgroups according to combinations of hemagglutinin (HA) and neuraminidase (NA) surface proteins. The influenza A virus has a wide host adaptation, ranging from avian to mammalian, but until recently has not been reported in dogs $(3,12,30)$. Influenza virus infection in dogs was first detected in the United States in 2004, and genetic analyses of the virus showed an equinederived influenza virus (H3N8) $(7,28)$. Initially, the canine influenza virus (CIV) in dogs was thought to occur because of contact with horses, but interspecies transmission of the CIV remained unclear (28). Since the first detection of the disease in dogs, different subtypes of the influenza virus, including $\mathrm{H} 5 \mathrm{~N} 1(23,25)$, H3N2 (23), H5N2 (9), H1N1 (14), and H3N1 (24), have been reported. Common clinical characteristics of the CIV range from mild respiratory disease to severe bronchopneumonia. CIV infection is evidenced by various clinical signs, including fever, persistent cough, nasal and ocular discharge, sneezing, anorexia, lethargy, weight loss, and severe bronchopneumonia. The most common pathological sign of the infection is damage of the tracheal epithelium (29). Because all respiratory pathogens are transmitted by direct contact and because the virus can survive for a long time in fomites, contaminated areas in kennels, shelters, dog competition areas, and veterinary clinics are responsible for the spread of the infection. Vaccination is an important factor for protection against the CIV, and vaccines are routinely used in the United States. After the disease was first seen in a dog in the United States, its presence has been reported in various other countries $(7,12)$. However, no serological or virological studies have been conducted on dogs in Turkey. The objective of the present study was to investigate the presence of CIV infection in shelter dogs in Turkey.

\section{Material and methods}

Study area. Erzurum is located in the East Anatolian province of Turkey and has an area of $25.355 \mathrm{~km}^{2}$ at an altitude of $1.853 \mathrm{~m}$. It has a humid continental climate with 
an annual average temperature of $5.6^{\circ} \mathrm{C}$ and an average rainfall of $33.8 \mathrm{~kg} / \mathrm{m}^{2}$.

Preparation of samples. Animal shelters accept new dogs at regular periods, and the dog population is renewed at certain times. Sampling was performed on a seasonal intake of new dogs into the animal shelter. A total of 208 paired blood and nasal swab samples were collected from dogs with respiratory and non-respiratory symptoms in various scheduled seasons: November 2015, and January, April, and June 2016. As influenza infection is more frequently observed during the cold rainy season, sampling was performed mostly in that period. Nasal secretions collected with sterile swabs were immediately treated with $1 \mathrm{~mL}$ sterile phosphate buffered saline (PBS) solution and transferred to the Virology Laboratory of the Veterinary Faculty at Ataturk University. In the laboratory, blood samples were centrifuged at $3.000 \times \mathrm{g}$ for $10 \mathrm{~min}$. Serum and swab samples were stored at $4{ }^{\circ} \mathrm{C}$ until the tests.

Enzyme-linked immunosorbent assay. A total of 208 sera samples were tested for antibodies to any subtype of the influenza A virus with a commercial blocking enzymelinked immunosorbent assay (ELISA) test kit (Influenza A $\mathrm{Ab}$ Test; Idexx Laboratories, Westbrook, ME, USA), which can detect anti-influenza A nucleoprotein antibodies. The test was performed according to the manufacturer's recommendations. First, all test kit reagents were brought to room temperature prior to use. ELISA plates coated with influenza A nucleoprotein were incubated with a tenfold mixture of $10 \mu 1$ of serum and $90 \mu 1$ of diluent for $60 \mathrm{~min}$ at room temperature. Next, unbound antibodies were removed by washing four separate times with $350 \mu \mathrm{l}$ of wash solution; then $100 \mu \mathrm{l}$ of the conjugate was dispensed into each well and incubated for $30 \mathrm{~min}$ at room temperature. After the plates had been washed four times to remove unbound material, $100 \mu 1$ of substrate was added to each well and incubated at room temperature for $15 \mathrm{~min}$. Finally, $100 \mu \mathrm{l}$ of stop solution was added, and the absorbance values were read at $650 \mathrm{~nm}$. Results obtained from a spectrophotometer were evaluated according to the $P I$ value $(P I \geq 0.6$, negative; $P I<0.6$, positive). For each test plate, positive and negative controls provided by the manufacturer were used. According to the manufacturer, the Influenza A Ab test kit has $99.7 \%$ specificity and $95.4 \%$ sensitivity.

Investigation of viral RNA. Ribonucleic acid (RNA) was extracted using the Viral Nucleic Acid Kit (Vivantis Technologies, Selangor, Malaysia) in accordance with the manufacturer's protocol. Detection of influenza A virus RNA was performed by reverse transcriptionpolymerase chain reaction (RT-PCR) with a single primer pair that targeted the conserved region of the HA2 gene of the influenza A virus genome. The primers used for the hemagglutinin subtypes of the influenza A virus were sense HA-1134: 5'- GGA ATG ATH GAY GGN TGG TAT GG -3', and anti-sense Bm-NS-890: 5' - ATA TCG TCT CGT ATT AGT AGAAAC AAG GGT GTTTT (Phipps et al. 2004). Thermal condition testing was performed as described by Phipps et al. (18).
This study was approved by the Animal Experiments Local Ethics Committee of the Ataturk University (2015/ 104-88). Financial support for the research was provided by the scientific research projects council at the Ataturk University (Project no: 2015/056).

Statistical analysis. Differences between the sexes were evaluated with the chi-square test. Statistical analysis was performed using the SPSS software version 16 (SPSS, Chicago, IL, USA).

\section{Results and discussion}

Samples were collected from 208 dogs from an animal shelter in the municipality of Erzurum over the study period from November 2015 to June 2016. Out of the 208 dogs, 94 (45.2\%) were male and 114 (54.8\%) were female; their average age was 4.7 years (Tab. 1 ).

Antibodies against the CIV were detected in 11 $(5.29 \%)$ dogs. The distribution of antibodies against the influenza A virus in dogs according to the sex and month is shown in Tab. 1 and 2, respectively. With regard to seasonal distribution, the highest rate of influenza A antibodies was detected in April (45.5\%), the rainiest season of the year, followed by November (36.4\%) and January (18.2\%), but no antibodies were detected in June (Tab. 2). A total of 208 swab samples were negative for influenza virus A RNA by RT-PCR. According to our CIV screening data, there is a risk of canine influenza infection in Turkey. No information about the status of the CIV in Turkey had previously existed. This is the first study of its kind to have been conducted in Turkey.

This study aimed to investigate the presence and prevalence of CIV infection, on which no virological or serological study had previously been conducted in Turkey.

Tab. 1. Distribution of canine influenza virus (CIV) antibody positivity among sexes

\begin{tabular}{|l|r|c|c|c|c|c|}
\hline \multicolumn{1}{|c|}{ Sex } & \multicolumn{1}{c|}{$\mathrm{n}$} & $\begin{array}{c}\text { Positive } \\
\mathrm{n}(\%)\end{array}$ & $\begin{array}{c}\text { Negative } \\
\mathrm{n}(\%)\end{array}$ & $\mathrm{X}^{2}$ & $\mathrm{df}$ & $\mathbf{P}$ \\
\hline Female & 114 & $7(6.1)^{\mathrm{a}}$ & $107(93.9)$ & & & \\
Male & 94 & $4(4.3)^{\mathrm{a}}$ & $90(95.7)$ & 0.365 & 1 & $\mathbf{P} \geq 0.05$ \\
\hline Total & 208 & $11(5.3)$ & $197(94.7)$ & & & \\
\hline
\end{tabular}

Tab. 2. Distribution of canine influenza virus (CIV) antibodies according to month $(\mathrm{n}=\mathbf{2 0 8})$

\begin{tabular}{|l|c|c|c|c|c|}
\hline & $\mathrm{n}$ & April \% & June \% & November \% & January \% \\
\hline 2015/16 & & & & & \\
CIV positive & 11 & $5(45.5)$ & $0(0.0)$ & $4(36.4)$ & $2(18.2)$ \\
CIV negative & 197 & $86(43.7)$ & $11(5.6)$ & $46(23.4)$ & $54(27.4)$ \\
Total & 208 & $91(43.8)$ & $11(5.3)$ & $50(24.0)$ & $56(26.9)$ \\
\hline *Average temperature ('C) & 5.5 & 14.9 & 0.7 & -9.3 \\
\hline *Average rainy days & 14.2 & 11.0 & 9.2 & 11.3 \\
\hline
\end{tabular}

Explanations: *The average temperatures and the average number of rainy days for the province of Erzurum between 1950 and 2015 were calculated according to data obtained from the Republic of Turkey Ministry of Forestry and Water Affairs, General Directorate of Meteorology. 
Influenza virus is a pathological agent for humans, birds, and mammals. Influenza viruses, which are closely related to each other, have the capability to mutate (reassort) via their genomes, and this enables interspecies transmission. Although it has also been stated that human influenza viruses have a low potential for transmission to canines, studies have shown that the potential for transmission of CIVs to humans should not be ignored (10).

Canine influenza is characterized by fever, productive cough, progressive dry cough, and nasal discharge (5). Because the virus can survive for two days on contaminated surfaces, four days in water, and one day on clothes without losing its infectious ability, areas such as playgrounds, shelters, and pet shops where dogs are housed together present a great risk of infection with the disease. There is, especially, a risk of infection for unvaccinated dogs or dogs with decreased antibody titration (27). In the presented study, the environment in which the animals were housed also fits this description.

After the disease was first seen in a greyhound dog in the United States in 2004, it was found that CIV infection was not specific to a single species, but could be observed in all dog species (12). Crawford et al. (7) determined the prevalence of the disease in dog shelters and veterinary clinics to be $97 \%$ in the United States in 2005. Barrel et al. (2) detected 2.9\% (4/140) and $4.5 \%(5 / 110)$ positivity in sera obtained from 140 veterinary clinics and 110 hospital polyclinics in the US state of Colorado in 2010 and reported that the prevalence in Colorado dogs was low. Pecoraro et al. (16) assessed 5.160 sera and nasal swabs obtained from dog shelters in six states in the United States in 2014 using the hemagglutination inhibition (HI) test and reported positivity rates of $4.4 \%$ in New York, $4.7 \%$ in Colorado, 3.2\% in South Carolina, 1.2\% in Florida, and $0 \%$ in California and Texas. While the highest seropositivity was found in Colorado (10\%), followed by New York (8.5\%), no positivity was found in dogs in the other shelters (16). Kruth et al. (12) reported that the prevalence of CIV infection in Ontario, Canada, was $0.4 \%(1 / 225)$ in 2008 and that it was identified in a greyhound dog in Florida. Pecoraro et al. (17) also assessed the sera of 399 Alaskan sled dogs in 2012 using the HI test, but found no positivity. Also, it was observed that 39 dogs were vaccinated and demonstrated seropositive results by the virus neutralization test, so the effectiveness of vaccination in the dog population was emphasized (17). On the other hand, no CIV antibodies were detected in 251 dogs in New Zealand (11). The dogs making up the population in the present study were sampled randomly from an animal shelter that had the ability to detect the disease. Despite the high prevalence observed in the United States, this rate was found to be $5.3 \%$ in this study.
The prevalence of the disease in Europe, specifically in the United Kingdom, has been reported to be $90 \%$ in foxhounds dogs (15). The prevalence of CIV infection in Italy was also reported to be high $(4,20)$. De Benedicts et al. (4) detected a high antibody positivity by the complement-enzyme linked immunosorbent assay (C ELISA) in 6.885 samples obtained from dogs in 2010, while Pratelli and Colao (20) found the positivity rate by C ELISA to be $3.56 \%$ in 564 serum samples obtained from pet and shelter dogs in 2014. Low seropositivity rates were reported in some studies conducted in Germany $(8,21)$. Damiani et al. (8) observed a seropositivity of $0.13 \%$ in 736 sera samples from dogs. However, in 2014, Schulz et al. (21) failed to detect CIV antibodies in 272 healthy dogs or in 35 dogs with the respiratory disease. It is worth noting that the prevalence $(5.3 \%)$ determined in the present study among randomly sampled dogs from an animal shelter was lower than that in England, but higher than those in both Italy and Germany.

There are reports of CIV prevalence from countries of the Far East, especially China $(6,26,28)$, Korea $(1,13)$, Bangladesh (22), and Thailand (19). Lee et al. (13) reported 14\% seropositivity in 68 of 361 farm dogs, in 2 of 419 pet dogs, and in 7 of 49 dogs in four regional Korean animal hospitals. Also, An et al. (1) identified antibody positivity in 19 of 385 dogs in 2010. Zhang et al. (28) identified seropositivity by ELISA in $45(20.2 \%)$ of 223 feral dogs and $166(33.2 \%)$ of 500 pet dogs in northeast China. Chow and He (6) identified it by ELISA in $31(6.71 \%)$ of 462 pet dogs in a Chinese province of Shenzhen, whereas $\mathrm{Su}$ et al. (26) detected it in 66 (12.2\%) of 540 farm dogs and in $48(5.3 \%)$ of 900 pet dogs in the Guandong province of China and reported an increasing prevalence in this area. The seropositivity $(5.3 \%)$ in the present study was lower than that in the above countries. Sen et al. (22) did not find any positivity in nasal swabs from 50 dogs in various regions of Bangladesh. Posuwan et al. (19) detected $2.94 \%$ positivity in nasal swabs obtained from 102 healthy dogs and 109 dogs with respiratory disease in Thailand in 2010. It is remarkable that the seropositivity determined in our study $(5.3 \%)$ was higher than that in these two countries.

The sampling tests in the present study were conducted in April, June, November, and January. With reference to the annual average rainfall and temperature reported by the Turkish Republic General Directorate of Meteorology, it was observed that the highest positivities occurred in April (45.5\%) and November $(46.4 \%)$, when the rate of rainfall was high and the temperature was low. It is noteworthy that this condition was consistent with other studies.

Comparison of seropositivity rates in the two sexes showed that it was relatively higher in the females $(6.1 \%)$ than in the males (4.3\%). However, Chow and 
He (6) detected that seropositivity was higher in male dogs $(7.78 \%)$ than in female dogs $(5.21 \%)$. Since the ages of the animals used in the present study were not precisely known, seropositivity in age groups was not compared. Chow and He (6) reported prevalence between $6.19 \%$ and $7.4 \%$ in different age groups of dogs in China's Shenzen province, with a high prevalence in animals between one and three years of age, and quite low in dogs younger than one year of age. Sen et al. (22) detected no antibodies against CIV in nasal swabs obtained from 50 dogs of different ages from various regions of Bangladesh.

The developed countries have the highest rates of CIV infection, which, as has been observed in many countries, is a major health problem for dogs, and influenza viruses with zoonotic potential must always be taken into consideration. Animal shelters, where animal numbers and inter-animal contact are high, play a significant role in the spread of the disease. Although CIV vaccines are routinely used in various countries of the world, they are not yet used in Turkey. This is a risk factor that should be taken into account for the dog population of our country. The fact that the results of screenings did not yield any data revealed that the status of CIV infection in Turkey needs to be clarified.

In conclusion, this study, the first of its kind in Turkey, revealed the presence of CIV infection. Thus, there is a distinct need for more multicentered virological and serological studies to be performed on larger populations. The disease exists in Turkey, as in many other countries of the world, but there is still time to take precautions, as its prevalence is currently low.

\section{References}

1. An D. J., Jeoung H. Y., Jeong W., Chae S., Song D. S., Oh J. S., Park B. K.: A serological survey of canine respiratory coronavirus and canine influenza virus in Korean dogs. J. Vet. Med. Sci. 2010, 72, 1217-1219.

2. Barrell E. A., Pecoraro H. L., Torres-Henderson C., Morley P. S., Lunn K. F., Landolt $G$. A.: Seroprevalence and risk factors for canine H3N8 influenza virus exposure in household dogs in Colorado. J. Vet. Intern. Med. 2010, 24, 1524-1527.

3. Beladi S. P., Ghorashi S. A., Morshedi D.: Using Nested-PCR for Detection of Avian Influenza Virus. Acta Vet. Brno 2005, 74, 581-584.

4. Benedictis P. De, Anderson T. C., Perez A., Viale E., Veggiato C., Tiozzo Caenazzo S., Crawford P. C., Capua I.: A diagnostic algorithm for detection of antibodies to influenza A viruses in dogs in Italy (2006-2008). J. Vet. Diagn. Invest. 2010, 22, 914-920.

5. Buonavoglia C., Martella V.: Canine respiratory viruses. Vet. Res. 2007, 38, 355-373.

6. Chow W., He H. Z.: Seroprevalence of avian cause H3N2 canine flu infection disease in pet dogs in Shenzhen, China. Afr. J. Infect. Dis. Res. 2014, 1, 50-52.

7. Crawford P. C., Dubovi E. J., Castleman W. L., Stephenson I., Gibbs E. P., Chen L., Smith C., Hill R. C., Ferro P., Pompey J., Bright R. A., Medina M. J., Johnson C. M., Olsen C. W., Cox N. J., Klimov A. I., Katz J. M., Donis R. O.: Transmission of equine influenza virus to dogs. Science 2005, 310, 482-485.

8. Damiani A. M., Kalthoff D., Beer M., Müller E., Osterrieder N.: Serological survey in dogs and cats for influenza A(H1N1)pdm09 in Germany. Zoonoses. Public. Health 2012, 59, 549-552.

9. Guang-jian Z., Zong-shuai L., Yan-li Z., Jiang S. J., Xie Z. J.: Genetic characterization of a novel influenza A virus $\mathrm{H} 5 \mathrm{~N} 2$ isolated from a dog in China. Vet. Microbiol. 2012, 155, 409-416.
10.Jang H., Jackson Y. K., Daniels J. B., Ali A., Kang K. I., Elaish M., Lee C. W. Seroprevalence of three influenza A viruses (H1N1, H3N2, and H3N8) in pet dogs presented to veterinary hospital in Ohio. J. Vet. Sci. 2016, 155, 409-416.

11. Knesl O., Allan F. J., Shields S.: The seroprevalence of canine respiratory coronavirus and canine influenza virus in dogs in New Zealand. N. Z. Vet. J. 2009, 57, 295-298

12. Kruth S. A., Carman S., Weese J. S.: Seroprevalence of antibodies to canine influenza virus in dogs in Ontario. Can. Vet. J. 2008, 49, 800-802.

13. Lee C., Song D., Kang B., Kang D., Yoo J., Jung K., Na G., Lee K., Park B., $O h J$ : A serological survey of avian origin canine H3N2 influenza virus in dogs in Korea. Vet. Microbiol. 2009, 137, 359-362.

14.Lin D., Sun S., Du L., Ma J., Fan L., Pu J., Sun Y., Zhao J., Sun H., Liu J.: Natural and experimental infection of dogs with pandemic H1N1/2009 influenza virus. J. Gen. Virol. 2012, 93, 119-123.

15. Newton R., Cooke A., Elton D., Bryant N., Rash A., Bowman S., Blunden T., Miller J., Hammond T. A., Camm I., Day M.: Canine influenza virus: Cross species transmission from horses. Vet. Rec. 2007, 161, 142-143.

16. Pecoraro H. L., Bennett S., Huyvaert K. P., Spindel M. E., Landolt G. A.: Epidemiology and ecology of H3N8 canine influenza viruses in US shelter dogs. J. Vet. Intern. Med. 2014, 28, 311-318.

17. Pecoraro H. L., Lee J. S., Achenbach J., Nelson S. Jr, Landolt G. A.: Seroprevalence of canine influenza virus (H3N8) in Iditarod racing sled dogs. Can. Vet. J. 2012, 53, 1091-1104.

18. Phipps L., Essen S., Brown I.: Genetic subtyping of influenza A viruses using RT-PCR with a single set of primers based on conserved sequences within the HA2 coding region. J. Virol. Methods 2004, 122, 119-122.

19. Posuwan N., Payungporn S., Thontiravong A., Kitikoon P., Amonsin A., Poovorawan Y.: Prevalence of respiratory viruses isolated from dogs in Thailand during 2008-2009. Asian Biomedicine 2010, 4, 563-569.

20. Pratelli A., Colao V.: A population prevalence study on influenza infection in dogs in Southern Italy. New Microbiol. 2014, 37, 277-283.

21. Schulz B., Klinkenberg C., Fux R., Anderson T., Benedictis P. de, Hartmann K. Prevalence of canine influenza virus A (H3N8) in dogs in Germany. Vet. J. 2014, 202, 184-185.

22.Sen S., Rahman S., Nag M., Rahman M. M., Sarker R. R., Kabir S. M.: Prevalence of canine parvovirus and canine influenza virus infection in dogs in Dhaka, Mymensingh, Feni and Chittagong districts of Bangladesh. Asian J. Med. Biol. Res. 2016, 2, 138-142.

23. Song D., Kang B., Lee C., Jung K., Ha G., Kang D., Park S., Park B., Oh J.: Transmission of avian influenza virus (H3N2) to dogs. Emerg. Infect. Dis. 2008, 14, 741-746.

24. Song D., Moon H. J., An D. J., Jeoung H. Y., Kim H., Yeom M. J., Hong M., Nam J. H., Park S. J., Park B. K., Oh J. S., Song M., Webster R. G., Kim $J$. K., Kang B. K.: A novel reassortant canine H3N1 influenza virus between pandemic H1N1 and canine H3N2 influenza viruses in Korea. J. Gen. Virol. 2012, 93, 551-554.

25.Songserm T., Amonsin A., Jam-on R., Sae-Heng N., Pariyothorn N., Payungporn S., Theamboonlers A., Chutinimitkul S., Thanawongnuwech R., Poovorawan Y.: Fatal avian influenza A H5N1 in a dog. Emerg. Infect. Dis. 2006, 12, 1744-1747.

26. Su S., Chen Y., Zhao F. R., Chen J. D., Xie J. X., Chen Z. M., Huang Z., Hu Y. M., Zhang M. Z., Tan L. K., Zhang G. H., Li S. J.: Avian-origin H3N2 canine influenza virus circulating in farmed dogs in Guangdong, China. Infect. Genet. Evol. 2013, 19, 251-256.

27. Wiley C. A., Ottoson M. C., Garcia M. M., Wiley L. E., Otto C. M.: The Seroprevalence of Canine Influenza Virus H3N8 in Dogs Participating in a Flyball Tournament in Pennsylvania in 2010: A Follow-Up Study. J. Vet. Intern. Med. 2013, 27, 367-370.

28. Zhang Y. B., Chen J. D., Xie J. X., Zhu W. J., Wei C. Y., Tan L. K., Cao N., Chen Y., Zhang M. Z, Zhang G. H., Li S. J.: Serologic reports of H3N2 canine influenza virus infection in dogs in northeast China. J. Vet. Med. Sci. 2013, 75, 1061-1062.

29. Zhao F. R., Li S. J., Zhou D. H., Chen N., Zhang Y. Z., Qi W. B., Jiao P. R., Liao M., Tong G. Z., Zhang G. H.: Seroprevalence of avian origin H3N2 canine influenza virus infection in pet dogs in Shenzhen, China. Afr. J. Microbiol. Res. 2011, 5, 5960-5963.

30. Zhou P., Huang S., Zeng W., Zhang X., Wang L., Fu X., Li S.: Seroepidemiological Evidence of Subtype H3N8 Influenza Virus Infection among Pet Dogs in China. PloS One 2016, 11, 1-7.

Corresponding author: Assist. Prof. Dr. Hakan Aydin (DVM, Ph.D.), Ataturk University, Faculty of Veterinary Medicine, Department of Virology, 25240, Erzurum, Turkey; e-mail: hakanaydin.dr@gmail.com 